\title{
O DISCURSO SOBRE GÊNERO NO CURRÍCULO DO MUNICIPIO DE TERESINA: Reinvenção do conservadorismo?
}

Neide Cavalcante Guedes ${ }^{(*)}$

As discussões em torno do conceito de ideologia e as relações que com este se estabelecem, as questões de gênero, raça e credo, encontram-se em evidência no panorama social brasileiro considerando se tratarem de temáticas geradoras de polêmica, seja no campo social, seja no campo educacional.

Para melhor compreender a amplitude desse conceito buscamos o pensamento de Chauí $(1985$, p.65) que nos orienta a entender ideologia como

\begin{abstract}
[...] o sistema ordenado de ideias ou representações e das normas e regras como algo separado e independente das condições materiais, visto que seus produtores - os teóricos, os ideólogos, os intelectuais - não estão diretamente vinculados à produção material das condições de existência. E, sem perceber, exprimem essa desvinculação ou separação através de suas ideias. Ou seja, as ideias aparecem como produzidas somente pelo pensamento, porque os seus pensadores estão distanciados da produção material.
\end{abstract}

No campo do currículo, Apple (1982), explica que ideologia pode ser compreendida como um tipo falso de consciência que obriga toda sociedade a descobrir o mundo sob a ótica de um grupo determinado, ou sob a ótica das classes dominantes que impõem uma forma de pensar e de agir.

Nessa perspectiva e, partindo do pensamento de Bakhtin (1997), entendemos que a natureza de toda linguagem é eminentemente ideológica e que todo signo é ideológico, marcado como uma realidade ideológica, que tem sua materialidade e que se edifica no ambiente social da comunicação pela interação verbal. O autor (p. 32) afirma que:

Um produto ideológico faz parte de uma realidade (natural ou social) como todo corpo físico, instrumento de produção ou produto de consumo; mas, ao contrário destes, ele também reflete e refrata uma outra realidade, que lhe é exterior. Tudo que é ideológico possui um significado e remete a algo situado fora de si mesmo. Em outros termos, tudo o que é ideológico é um signo. Sem signos não existe ideologia. [...]. A existência do signo nada mais é do que a

\footnotetext{
${ }^{(*)}$ É mestre em Educação pela Universidade Federal do Piauí (2002) e doutora em Educação pela Universidade Federal do Rio Grande do Norte (2006). É professora do Programa de Pós-graduação em Educação da Universidade Federal do Piauí.
} 
materialização de uma comunicação. É nisso que consiste a natureza de todos os signos ideológicos.

Partindo do pensamento do autor, fica evidente que as questões ideológicas estão presentes na vida do sujeito, cujo significado vai além desse próprio sujeito, considerando que o signo reflete na medida em que faz referência a uma realidade e refrata porque no conjunto de valores que o sujeito tem um predomina e outros se escondem, isso porque um mesmo signo pode ter significados diversos e isso vai depender da situação social e histórica, pois qualquer discurso se institui como diálogo entre vários enunciados.

Com essa compreensão, o presente artigo objetiva discutir o avanço do conservadorismo no currículo da rede municipal de educação da cidade de Teresina, capital do estado do Piauí a partir do Projeto de Lei 20/2016 aprovado pela Câmara Municipal que trata da proibição de livros, materiais didáticos ou qualquer outro meio contendo ideologia de gênero nas Escolas Infantis do município de Teresina, ou seja, o teor do projeto se reveste de elementos contrários a toda e qualquer possibilidade de discussão nas escolas municipais sobre ideologia de gênero, conforme estabelece o seu artigo $1^{\circ}$ :

Art. $\mathbf{1}^{\mathbf{0}}$. Fica proibida a distribuição, utilização, exposição, apresentação, recomendação, indicação e divulgação de livros, publicações, projetos, palestras, folders, cartazes, filmes, vídeos, faixas ou qualquer tipo de material, lúdico, didático ou paradidático, físico ou digital, contendo manifestações da ideologia de gênero nos estabelecimentos de ensino da rede pública municipal da cidade de Teresina.

Parágrafo único. O material a que se refere o caput deste artigo é todo aquele que inclua em seu conteúdo informações sobre a prática da orientação ou opção sexual, da igualdade e desigualdade de gênero, de direitos sexuais e reprodutivos, da sexualidade polimórfica, da desconstrução da família e do casamento, ou qualquer manifestação da ideologia de gênero.

De acordo com o legislativo municipal da cidade de Teresina, essa conduta se enquadra no estabelecido da Convenção Americana sobre direitos humanos assinada na Conferência Especializada Interamericana sobre Direitos Humanos em San José, Costa Rica, em 22 de novembro de 1969 no artigo 12 inciso 4 e reforçada no texto constitucional de 1988.

Artigo 12. Liberdade de consciência e de religião.

4. Os pais, e quando for o caso os tutores, têm direito a que seus filhos ou pupilos recebam a educação religiosa e moral que esteja acorde com suas próprias convicções.

Considerando o artigo $1^{\circ}$ do Projeto de Lei da Câmara Municipal de Teresina e o artigo 12 da Convenção Americana, fica evidente o entendimento dos parlamentares no sentido de propor 
uma centralização do currículo na qual o conhecimento a ser trabalhado na formação das crianças e jovens seja rigoroso e excludente em relação às questões culturais, pois tudo leva a crer que essas questões - culturais - não se revestem de significado científico.

Com base nas colocações apresentadas, temos o propósito de compreender o que significa retirar essa discussão do campo das políticas curriculares, considerando a forte resistência instaurada no âmbito da Câmara Municipal de Teresina no que diz respeito à ideologia de gênero nas escolas da rede municipal.

Como formadora nos cursos de licenciatura essas discussões circulam e mobilizam diferentes contextos e são trazidas nas observações que os alunos fazem bem como da prática de estudantes que já atuam como docentes. Pautar essa discussão se alinha ao compromisso de não limitar o conhecimento somente àquele definido nos currículos e que muitas vezes se constituem na reprodução teórica revelando assim a necessidade de estabelecer uma relação entre o conhecimento e a cultura no âmbito do currículo da rede municipal, no sentido de compreender o que está sendo chamado de conhecimento e como as questões culturais perpassam essa compreensão. Além disso, ainda que a temática de gênero não seja o foco direto das pesquisas que tenho desenvolvido, a discussão tangencia as pesquisas sobre gestão curricular, profissionalidade docente que tenho desenvolvido. "É importante compreender que a profissionalidade do educador se expressa a partir da possibilidade que este tem para refletir sobre as experiências vividas tendo clareza de que a profissão docente garante diferentes dinâmicas” (GUEDES e MONTEIRO, 2015, p. 434).

Os estudos de Apple, citados por Lopes e Macedo (2011, p. 31) nos orientam no sentido de compreender que:

As ideologias são um sistema de crenças partilhadas que nos permite dar sentido ao mundo, uma teia de argumentação que visa a legitimar determinada visão de mundo. Nesse sentido, quando hegemônicas, ocultam as contradições sociais.

A escola constitui-se lócus legítimo na conjuntura das instituições sociais como responsável em formar/preparar o indivíduo para viver em contextos sociais. Para tanto, a escola se organiza conforme as exigências e necessidades desta sociedade e se apresenta de forma diretamente relacionada a este espaço social, seguindo os diferentes momentos da história do seu próprio surgimento e da sua evolução.

Nesta perspectiva, a escola, como instituição social, desenvolve igualmente uma função social, ou seja, com atribuições baseadas nas necessidades que são socialmente produzidas, evidenciadas e solicitadas institucionalmente de modo que a formação escolar recebida pelos alunos atenda as exigências no âmbito social. 
Gómez (2000, p. 13), ao discutir a importância do processo educativo na evolução humana, defende que "[...] a educação, num sentido amplo, cumpre uma iniludível função de socialização, desde que a configuração social da espécie se transforma em um fator decisivo de hominização e em especial da humanização do homem".

Com base no pensamento do autor referido podemos apreender que é no contexto educacional no qual a cultura deve se manifestar, por ser ali que temos a possibilidade de construir conhecimentos embasados nesta cultura e assim dar continuidade ao processo de socialização do homem.

Quando trazemos o Projeto de Lei aprovado pela Câmara Municipal de Teresina para o campo das discussões sobre gênero fica evidente uma pressão forte por parte dos parlamentares que apoiaram o referido Projeto e que se manifesta nas suas entrelinhas no sentido de que a escola enquanto espaço sistematizado de construção de conhecimento deve focar nesse conhecimento. É como dizer que a escola existe para ensinar conteúdos e que a discussão sobre gênero, raça, religião não se constitui em conteúdos e que, portanto, não é conhecimento.

Nessa perspectiva é relevante destacar qual a concepção de conhecimento que perpassa o entendimento da sociedade teresinense e como esta postura pode contribuir positiva ou negativamente na condução do desenvolvimento e da aprendizagem dos alunos da Rede Municipal.

Segundo as Diretrizes Curriculares do Município de Teresina (2008), as relações que se estabelecem entre a escola e a sociedade são complexas se considerarmos a dinâmica contraditória que as integra, uma vez que a escola colabora tanto para a conservação da estrutura social de desigualdade quanto oferece instrumentos participativos capazes de transformar essa mesma sociedade. Nesta direção e, tomando as determinações contidas nas Diretrizes Curriculares do Município de Teresina (p. 131),

A escola atua, assim, no espaço da cultura, mediando relações de poder no âmbito da construção da cidadania. Desse modo, a cultura é concebida como esse meio ambiente humano. Portanto, a cultura é, ao mesmo tempo, processo e produto que constituem o homem e que são por ele criados.

Assim a escola materializa-se como espaço de relações políticas em que se busca o diálogo público sobre o acesso e a utilização intencional do conhecimento, conforme o interesse dos grupos e sujeitos sociais, uma vez que essas múltiplas dimensões ao se articularem na dinâmica da educação escolar irão fazer da escola um organismo de cidadania, como estabelece a Lei de Diretrizes e Bases da Educação Nacional (Lei 9.394), art. 2: 
A educação, dever da família e do estado, inspirada nos princípios de liberdade e nos ideais e solidariedade humana, tem por finalidade o pleno desenvolvimento do educando, seu preparo para o exercício da cidadania e sua qualificação para o trabalho.

A Lei destaca, ainda, que os princípios ali estabelecidos devem ser cumpridos e respeitados para que efetivamente o seu artigo $2^{\circ}$ possa ser plenamente favorecido. No entanto são nos princípios que encontramos a contradição quando a lei dita que dentre os princípios que darão sustentação ao ensino localizamos o Inciso IV - respeito à liberdade e apreço à tolerância.

O Projeto de Lei da Câmara Municipal de Teresina fere de forma violenta esse princípio, na não aceitação das diferenças. Promovida pelo conhecimento, pela abertura de espírito, pela comunicação e liberdade de pensamento, de consciência e de crença, a tolerância é a harmonia na diferença, ou seja, os seres humanos, que se caracterizam naturalmente pela diversidade de seu aspecto físico, de sua situação, de seu modo de expressar-se, de seus comportamentos e de seus valores, têm o direito de viver em paz e de serem tais como são.

Compreender a importância desse princípio na Lei de Diretrizes e Bases da Educação Nacional passa pela necessidade de analisar o currículo a fim de identificar como o conhecimento está associado à cultura no sentido de perceber, no âmbito da escola, as diferenças ali presentes e que muitas vezes são eliminadas pela homogeneização.

Portanto, o que tal movimento de retirada da "ideologia de gênero" da pauta das escolas sugere é o entendimento do conceito de gênero fundamentado em parâmetros científicos de produção de saberes sobre o mundo, desconsiderando processos históricos e culturais que classificam e posicionam as pessoas a partir de uma relação sobre o que é entendido como feminino e masculino. Nessa perspectiva o conceito de gênero cria sentido para as diferenças percebidas em nossos corpos ao mesmo tempo em que articula pessoas, emoções, práticas e coisas dentro de uma estrutura de poder.

\section{CURRÍCULO, CONHECIMENTO E CULTURA: CONCEITOS QUE SE CRUZAM NA CONTRADIÇÃO DIVERSIDADE/DIFERENÇA}

Para melhor compreender o ambiente em que as questões sobre ideologia de gênero estão se manifestando é necessário entender o que significam os conceitos que dão origem ao título deste tópico. O que é o currículo? Como o conhecimento e a cultura se entrelaçam nesse instrumento de poder? Discutir o currículo é também discutir sobre o conhecimento que se apresenta envolvido nos diversos contextos culturais. Daí afirmarmos que não é possível compreender o currículo sem o conhecimento e a cultura que o atravessa. 
De acordo com Pacheco (2000, p. 29), o currículo pode ser considerado "um plano de intenções que assume uma proposta de cunho político, a qual reflete as opções fundamentais do nível de formação". O autor compreende o currículo como intenção, realidade e como fruto de um determinado contexto e resultado de decisões adotadas em outros vários contextos. Nessa mesma direção Macedo (2000, p. 43) nos orienta que o currículo

[...] é uma construção de atores e atrizes educativos de natureza ideológica, plural e encarnada.

Dessa forma é histórico e contextualizado. Constitui um processo identitário das práticas educativas de uma instituição, em meio à diversidade de suas relações.

Assim, trabalhar o currículo a partir das necessidades de formação expressas pela humanidade se constitui na possibilidade de garantir o poder agregador de bens culturais ao conhecimento, o que faz com que tudo isso se reflita no contexto social mais amplo. Significa, conforme estabelece Moreira (2001), pensar o currículo e a formação em uma sociedade cada vez mais multi onde as culturas, etnias, visões de homem e de mundo penetrem cada vez mais nos vários lócus.

Diante do quadro, o conceito de cultura se insere nesta discussão como um elemento importante no que se refere aos conteúdos e práticas considerados relevantes num dado momento histórico, e que são trazidos para a escola, para ali serem operacionalizados. É, portanto, nesta perspectiva que Veiga-Neto (2004, p. 167) define cultura como "[...] toda e qualquer manifestação humana que se dê no âmbito dos costumes, dos valores, das crenças, do simbólico, da fabricação de coisas, das práticas sociais, da estética, das formas de expressão etc.”.

Nesse sentido compreendemos que a cultura está posicionada sobre fronteiras que ao mesmo tempo se tocam e se cruzam constituindo novas significações e o que estamos denominando de fronteira ou limite é o que sucede toda a ação dinâmica da cultura pela determinação ideológica de seus significados. Portanto, a cultura é um campo de luta pelo poder.

O conceito de cultura é empregado notadamente por aqueles que trabalham no campo do currículo a partir de uma perspectiva pós-estrutural, de que cultura e linguagem se fundem para daí construir novos significados. Nessa direção Lopes e Macedo (2011, p. 203) afirmam que não tratam a cultura como objeto de ensino nem apenas como a produção cotidiana de nossas vidas. Estamos operando com uma compreensão mais ampla de cultura como aquilo mesmo que permite a significação. O currículo age como cultura e a cultura é a própria produção de sentidos dentro de um sistema de significação. 
Fica evidente para as autoras que não é possível compreender conhecimento sem ter a clareza de que essa compreensão perpassa as diferentes possibilidades de se discutir o currículo. É nessa direção que Silva (2001) nos orienta no sentido de perceber o conhecimento que constitui o currículo não como a reprodução de algo que está para além dele, mas como uma explicação especial dentre as muitas que poderiam igualmente ser produzidas, ou seja, o currículo como operação de bricolagem e o conhecimento como invenção produzida na relação em que o sujeito não é menos artificial que o objeto.

$\mathrm{Na}$ perspectiva de discutir currículo, cultura e conhecimento na contradição diferença/diversidade, trazemos o pensamento de Bhabha (1998, p. 63) para realçar que é possível estabelecer uma distinção entre o conceito de diversidade e o conceito de diferença.

A diversidade cultural é um objeto epistemológico - a cultura como objeto do conhecimento empírico - enquanto a diferença cultural é o processo da enunciação da cultura como "conhecivel", legítimo, adequado à construção de sistemas de identificação cultural.

$\mathrm{O}$ autor argumenta ainda que

Se a diversidade é uma categoria da ética, estética ou etnologia comparativas, a diferença cultural é um processo de significação através do qual afirmações $d a$ cultura ou sobre a cultura diferenciam, discriminam e autorizam a produção de campos de força, referência, aplicabilidade e capacidade.

Em diálogo com Bhabha, é possível compreender que as diferenças culturais que permeiam as discussões sobre gênero no espaço escolar pautam-se por relações de poder que oprimem determinados grupos e indivíduos e que respondem por crescentes xenofobias, racismo, homofobias, dentre outros. Tais respostas tanto têm correspondido à intenção de harmonizar e integrar os diferentes grupos no seio do que se chamaria de cultura hegemônica, como ao propósito de tornar visíveis, questionar e desestabilizar as assimétricas relações entre esses mesmos grupos. Isso porque a cultura enquanto tradição relativista da diversidade admite um sistema essencial enquanto que na diferença ela é percebida como um problema uma vez que seu significado deve ser elaborado considerando as diferentes classes, credos, raças e gênero.

Nos escritos de Skliar (2003) identificamos o argumento no sentido de compreender que diversidade e diferença resguardam posicionamentos diferentes apesar de serem habitualmente tomados no discurso educacional como termos iguais, visto que seu caráter de representação da alteridade parece idêntico. Isso faz com que, muitas vezes, a noção de diversidade acabe sendo empregada em torno da falsa ideia de uma equivalência entre as mais diversas culturas.

Skliar (2002, p. 201-2) acrescenta ainda que 
Entre a diversidade e a diferença existe um abismo insondável, uma distância política, poética e filosoficamente opressora. O outro da diversidade e o outro da diferença constituem outros dissimilares. A tendência de fazer deles o mesmo retorna todo discurso a seu trágico ponto de partida colonial, ainda que vestido com a melhor roupagem do multiculturalismo - mesmo que seja igualitarista ou diferencialista. Há uma política, uma poética e uma filosofia da diferença. Mas como descrever essas questões em inventar novamente o outro, sem mascará-lo, sem designá-lo, sem emudecê-lo, sem deixá-lo tenso com a fixação do diferente, sem constituí-lo num simples ventríloquo da nossa mesmidade, sem transformá-lo em uma espacialidade exterior da nossa (in) diferença?

Essa perspectiva se aproxima do que Homi Bhabha aponta a respeito do conceito de diversidade cultural ao fazer referência a cultura como um objeto do conhecimento empírico, que reconhece conteúdos e costumes culturais. Nesse caso a diversidade representa uma retórica radical da separação de culturas totalizadas, que se fundamentam na utopia de uma identidade coletiva única.

Em oposição a esta perspectiva essencialista, a diferença cultural se constitui como o processo de enunciação da cultura. Trata-se, conforme destaca Bhabha (1998, p. 63) de "um processo de significação através do qual afirmações $d a$ cultura e sobre a cultura diferenciam, discriminam e autorizam a produção de campos de força, referência, aplicabilidade e capacidade". Seria dizer que a diferença se compõe na tensão entre os enunciados e o processo de enunciação.

É com essa compreensão sobre currículo, cultura e conhecimento que discutimos o posicionamento do legislativo e da sociedade civil sobre a retirada das discussões sobre ideologia de gênero no espaço sistematizado das escolas municipais de Teresina.

\section{DISPUTAS EM TORNO DA IDEOLOGIA DE GÊNERO}

Nesta seção põe-se em análise o PL 20/2016 que proíbe o debate sobre as questões de gênero nas escolas de educação básica da rede municipal da capital. Para a construção dos dados que foram coletados diretamente nos sites da câmara de vereadores, da Universidade Federal do Piauí e do globo.com, buscamos os depoimentos de parlamentares, e da sociedade civil em geral, em entrevistas concedidas aos jornais e as assessorias de comunicação da Câmara Municipal de Teresina e da Universidade Federal do Piauí.

A partir da leitura criteriosa dessas entrevistas fomos extraindo passagens que demonstram as posturas assumidas pelos diversos segmentos no que diz respeito à aprovação do projeto de lei $\mathrm{n}^{\circ}$ 
20/2016 aprovado pela Câmara Municipal que trata da proibição de livros, materiais didáticos ou qualquer outro meio contendo ideologia de gênero nas Escolas Infantis do município de Teresina.

Durante o processo de análise e votação na Câmara de Vereadores, entidades se manifestaram contrárias à proposta e pediram ao prefeito a não aprovação da lei. O Projeto de Lei tem mobilizado forças de discussão contrária em Teresina como, por exemplo, alguns grupos de pesquisa da universidade, como também forças que defendem como, por exemplo, os religiosos.

Foi nesse cenário de disputas de poder que vários grupos-entidades ${ }^{1}$ organizaram uma aula pública em frente à Prefeitura Municipal de Teresina para tratar sobre o projeto de lei que proíbe a discussão de gênero nas escolas públicas da capital. Desde que foi aprovado pela Câmara de Vereadores, o PL tem sido o centro de muitas polêmicas.

No âmbito da Universidade Federal do Piauí foi realizada uma ampla discussão junto aos alunos no sentido de problematizar o que implical o fato de não permitir que a escola discuta questões dessa natureza. Essa discussão oportunizou aos alunos de todos os Centros de Ensino a se manifestarem e argumentarem sobre o projeto, que interfere diretamente nos seus processos formativos e, especificamente no caso dos alunos dos cursos de licenciatura, em sua atuação como docentes.

Vale destacar que uma cartilha explicativa sobre a Ideologia de Gênero foi distribuída pelo grupo favorável ao projeto com o intuito de explicar onde surgiu o termo, o conceito e os principais defensores de tal ideologia, além de trazer exemplos de livros didáticos e paradidáticos contendo tal pensamento.

De acordo com a autora do projeto, Vereadora Cida Santiago, a cartilha trata a Ideologia de Gênero como um "Cavalo de Tróia" que entra na escola disfarçada de orientação necessária ao combate à homofobia, machismo e construção de práticas sociais mais justas e igualitárias, mas na realidade tem efeitos extremamente nocivos para as crianças e para as famílias, pois contém informações impróprias e ofensivas ${ }^{2}$.

Na direção contrária, o Núcleo de Estudos e Pesquisas Educação, Gênero e Cidadania NUPEGECI da Universidade Federal do Piauí promoveu uma aula pública intitulada "Vamos conversar sobre gênero?”. A discussão teve lugar no auditório do Centro de Ciências Humanas e

\footnotetext{
${ }^{1}$ Universidade Federal do Piauí, Universidade Estadual do Piauí, Escolas de Educação Básica, Observatório de Juventudes e Violências na Escola (OBJUVE), Núcleo de Estudos em Gênero e Desenvolvimento (ENGENDRE), Grupo de Estudos SexGen (Sexualidade, Corpo e Gênero) e Comissão da Diversidade Sexual da OAB/PI.

2 Disp.: <http://www.teresina.pi.leg.br/noticia/cida-santiago-faz-pronunciamento-sobre-o-pl-202016-e-a-ideologia-degenero-nas-escolas $>$. Acesso em: 16 ago. 2016.
} 
Letras (CCHL) e contou com o apoio do Observatório de Juventudes e Violências na Escola, Núcleo de Estudos em Gênero e Desenvolvimento, Grupo de Estudos sobre Sexualidade, Corpo e Gênero e Comissão da Diversidade Sexual da OAB/PI.

Nesse contexto vale a pena destacar que pesquisas realizadas pelo Núcleo de Estudos e Pesquisas Educação, Gênero e Cidadania (NUPEGECI) da Universidade Federal do Piauí apontam o quanto a discriminação de gênero contra as pessoas que escapam dos padrões socialmente instituídos de identidade ou sexualidade tem desencadeado processos institucionalizados de discriminação, agressões e exclusão escolar contra aqueles que não se enquadram nesses padrões sociais convencionais, ou seja, gays, lésbicas, bissexuais, travestis.

A professora Shara Jane Adad, coordenadora do NUPEGECI, frisa que o Projeto de Lei fere a produção acadêmica que trata da temática de gênero. "Independente de existir diferentes centros de ensino na nossa instituição, como o Centro de Ciências da Educação (CCE) e Centro de Ciências da Natureza (CCN), é necessário compreender que há semelhanças para estabelecer diálogo. A oportunidade da aula "Vamos conversar sobre gênero?"seria, portanto, o ponto de encontro, em que diferentes grupos de pesquisa da UFPI se unem para discutir o Projeto de Lei" 3 .

Ao assumir essa postura de proibir uma discussão pertinente aos dias atuais, estamos cada vez mais negando a todos o direito constitucional à educação e inevitavelmente contribuindo para que as estatísticas apresentem o Brasil como um dos países mais preconceituosos e inseguros no mundo. A necessidade de romper com a ideia do essencialismo que provoca uma oposição binária, por exemplo, das categorias macho/fêmea, esconde diferenças, considerando que se o sujeito é puramente isso, ele não pode ser aquilo, uma vez que aquilo que se mantém sem alteração e que é construído em cada lado da oposição binária camufla o múltiplo jogo das diferenças e conserva sua irrelevância e invisibilidade.

Nessa perspectiva trazemos o manifesto de repúdio feito pelo Grupo de Estudos SexGen da Universidade Federal do Pará, que desenvolve trabalho em parceria com o NUPEGECI para apresentar os argumentos que são postos em debate.

Diante das recentes investidas da Câmara Municipal de Teresina contra as discussões de gênero nas escolas municipais, o grupo de pesquisa SEXGEN - Sexualidade, Corpo e Gênero - vem a público externar profundo repúdio ao obscurantismo e atraso representados pela maioria dos vereadores do município de Teresina, ao tentar impedir que crianças em idade escolar possam ter acesso a discussões sobre fatos tão relevantes para a sua formação como

\footnotetext{
3 Disp.: <http://www.ufpi.br/ultimas-noticias-ufpi/14341-nupegeci-ufpi-promove-aula-publica-intitulada-vamosconversar-sobre-genero >. Acesso em: 21 ago. 2016.
} 
cidadãos e cidadãs, e também para o melhor entendimento e solução das questões relativas às diversas formas de violência de gênero na nossa sociedade. [...]

[...] Nós que fazemos o SEXGEN, ao entender que temos uma função não apenas acadêmica, mas também de militância pela igualdade de gênero, apontamos o desserviço de se tentar impedir tais discussões na capital do estado que ocupa a quinta posição do país no ranking de feminicídios registrados, segundo o Atlas da Violência no Brasil, divulgado na última semana pelo Instituto de Pesquisas e Estudos Aplicados (IPEA). O mesmo levantamento mostra que o número de assassinatos de mulheres aumentou 142\% no Piauí, nos últimos dez anos. Não menos significativos são os dados relativos às diversas formas de violência contra os indivíduos LGBT, parcela da população que vive à margem, tendo direitos negados em função de suas orientações sexuais e identidades de gênero. [...]

[...] Levar questões de gênero à escola significa simplesmente debater as diversas formas de existência dos sujeitos, e as relações de poder que são naturalizadas na vida cotidiana. Assim, as raízes das diversas formas de violência contra as mulheres, da homofobia, e da transfobia, dentre outras, poderiam, talvez, começar a ser cortadas, ainda na infância. Ao tentar excluir a discussão de gênero das escolas municipais, a Câmara Municipal de Teresina está contribuindo para a perpetuação das violências de gênero, ao negar a diversidade $e$ invisibilizar parte da população que não se enquadra nos preceitos heteronormativos. E mais: excluir essa discussão configura-se também como exercício de violência simbólica contra famílias, contra crianças, contra cidadãos e cidadãs.

O PL em questão foi arquivado na Câmara de Vereadores. A autora do projeto condenou tal ação dizendo se tratar de uma manobra para que o mesmo não chegasse ao prefeito e deveria ter sido retomada em discussão plenária. Na crítica, reapresenta seu argumento em defesa do projeto: "Eles fizeram várias manobras para que o projeto não passasse do plenário. O que nós queríamos era apenas preservar as nossas crianças. Mas não vamos desistir". Jornal O Dia (2016). É $\quad$ nessa direção que Lopes e Macedo (2011, p.40) chamam a atenção no sentido de que "a capacidade de unificar um discurso é um ato de poder".

No pronunciamento da parlamentar fica evidente sua postura no sentido de compreender que tratar de gênero na escola é uma forma de agressão à família, que legitimamente se constitui na única e exclusiva responsável para tratar de assuntos dessa natureza. Ao inferir que a intenção dos vereadores signatários com ela do Projeto de Lei é a de preservação das crianças, evidencia uma postura que obscurece as diferenças nas mais diversas perspectivas; o direito à formação humana contextualizada reduz-se ao direito de aprender o básico expresso nos itens dos exames nacionais, agrupados em disciplinas isoladas em cada ano e reduzidos a listagem de conteúdos padronizados. 
Nesse contexto, trazemos o representante da igreja católica que também esteve na sessão, o padre Nilton Pereira, da Paróquia da Santíssima Trindade, no bairro Primavera. No G1 Piauí (Portal de notícias da Globo no Piauí), o sacerdote avalia que a proposta deveria ter sido aprovada e em poucas palavras disse que os direitos das crianças precisam ser protegidos. "Estamos aqui para proteger os direitos das nossas crianças. Discutir isso só irá induzir as crianças para o mal (sic) caminho" $^{4}$, afirmou o religioso.

A postura assumida pelo religioso se manifesta na crítica feita por Lopes e Macedo (2011, p.29) ao enfatizarem que "[...] a escola contribui para a legitimação de determinados conhecimentos e, mais especificamente dos grupos que o detêm”. Dialogando com as autoras em referência é possível ler que, na justificativa apresentada pelo sacerdote:

Abre-se uma nova tradição [...] entender que o currículo não forma apenas os alunos, mas o próprio conhecimento, a partir do momento em que seleciona de forma interessada aquilo que é objeto da escolarização (p.29).

A polarização nas discussões se evidencia e cria-se um binarismo que, por um lado, toma a diferença como algo a ser eliminado em nome do conhecimento e, por outro, gera uma problematização acerca do próprio papel da escola, como é possível antever na postura assumida pelo professor Júnior Vieira, da rede pública municipal de Teresina que, na condição de participante ativo do movimento contra o Projeto de Lei, afirma que o arquivamento é necessário. Segundo ele, a proibição das discussões de gênero nas escolas representaria um retrocesso. "O Projeto de Lei seria um retrocesso para a educação, porque impedia o discurso de gênero e estimulava o preconceito e as diferenças". O professor Júnior amplia suas colocações ao enfatizar que "os professores precisam discutir essas questões dentro de sala de aula até porque o nosso princípio é também falar sobre minorias, seja de questões raciais, crenças ou sobre sexualidade. Por isso, o nosso apelo pelo veto desse projeto continua". 5

A realidade educacional brasileira, especificamente a da cidade de Teresina, mostra o quanto este assunto é delicado, uma vez que o trabalho pedagógico ainda é realizado levando em consideração o que os sistemas estabelecem em seus currículos, distanciando, portanto, o trabalho do professor de uma análise histórica, sociológica e política de questões tão emergentes como é o caso do gênero na escola.

\footnotetext{
${ }^{4}$ Disponível em: <http://g1.globo.com/pi/piaui/noticia/2016/05/apos-tumulto-pl-sobre-discussao-de-genero-em-escolase-arquivado.html $>$. Acesso: 16 ago. 2016.

${ }^{5}$ Disponível em: <http://g1.globo.com/pi/piaui/noticia/2016/04/entidades-voltam-pedir-veto-pl-polemico-durante-aulapublica.html>. Acesso: 16 ago. 2016.
} 
Como enfatizado anteriormente, o referido Projeto mobilizou também outros segmentos como é o caso do Ministério Público na figura da promotora de justiça Mirian Lago que, em nota, afirmou que a Promotoria da Cidadania é "totalmente contra" o projeto de lei que proíbe o debate sobre questões de gênero na escola, pois, segundo ela, o Projeto em tese interfere nas políticas públicas afetando normas do Estado que garantem os direitos do cidadão. Com essa compreensão, a promotora enfatiza que "importante que fique claro que a nossa manifestação, em ser contra o PL, jamais vai de desencontro sobre a liberdade de crença e religião, que também é um direito garantido pela Constituição e deve ser exercida no âmbito da vida privada. No momento em que a lei afeta as políticas públicas e os direitos do cidadão, ela perde a validade e deixa de ter razão. Por isso, somos contra"6.

Outro aspecto de grande relevância para o que a promotora chama a atenção diz respeito às questões de saúde pública, considerando que os parlamentares que apoiaram a medida não se deram conta da dimensão dos prejuízos por ela causados. Na visão da promotora, "o PL afeta o âmbito da saúde porque impede a distribuição de materiais educativos que tratam do direito sexual e reprodutivo. Além de trabalhos, campanhas de conscientização nas escolas, tudo isso é um trabalho que vai ser perdido e que já é feito na capital".

Considerando as colocações da promotora, não podemos esquecer que vivemos num Estado laico no qual a liberdade de crença e convicções é garantida desde que exercida no âmbito pessoal dos indivíduos. Com isso, queremos chamar a atenção para o fato de que as normas do Estado que garantem o direito do cidadão não podem ser afetadas por convicções religiosas.

\section{CONSIDERAÇÕES SOBRE OS ESCRITOS}

O objetivo deste artigo foi, ao trazer o caso da discussão acerca da ideologia de gênero no currículo da rede municipal de educação da cidade de Teresina a partir do Projeto de Lei 20/2016 aprovado pela câmara municipal, problematizar um contexto que é observado em outros estados como, por exemplo, Paraíba e Alagoas. Discussões dessa natureza expressam uma perspectiva conservadora nas políticas educacionais marcada por um discurso calcado no conhecimento cientifico distanciado de uma perspectiva sociocultural.

O referido Projeto trata da proibição de livros, materiais didáticos ou qualquer outro meio contendo ideologia de gênero nas Escolas Infantis do município de Teresina e que ao provocar o

\footnotetext{
6 Disponível em: <http://g1.globo.com/pi/piaui/noticia/2016/03/pl-que-proibe-debate-de-generos-afeta-direitos-docidadao-diz-promotora.html. Acesso em: 16 ago. 2016.
} 
posicionamento dos diferentes segmentos da sociedade civil abriu espaço para que se trouxesse isso ao debate considerando que envolve a compreensão que se tem de conhecimento. A lógica da lei, conforme estabelecido, é a de que as discussões sobre gênero não podem ser incluídas em propostas curriculares por não se constituírem em conhecimento e que caberia à escola apenas ensinar o conteúdo das mais diversas áreas do conhecimento. Esta postura deixa claro que a visão de conhecimento dos segmentos conservadores da sociedade teresinense é a de que conhecimento não é cultura e sim ciência. Isso nos leva a indagar: e ciência não é cultura?

$\mathrm{Na}$ indagação está expresso que a escola precisa considerar o universo cultural dos alunos para pensar um planejamento curricular que atenda essa diversidade como possibilidade de desenvolver práticas satisfatórias, uma vez que o currículo, ao assumir sua condição de produtor de culturas diversas capaz de propor novas formulações dessa cultura dita universal, precisa compreender, como nos orienta Macedo (2006, p. 288), que

[...] a produção dos currículos formais e a vivência do currículo são processos cotidianos de produção cultural, que envolvem relações de poder tanto em nível macro quanto micro. Em ambos são negociadas diferenças. De ambos participam sujeitos culturais com seus múltiplos pertencimentos.

Pode parecer um lugar-comum, mas enquanto profissionais da Educação seja como docentes, seja como pesquisadores, é preciso estar sempre atentos às questões que envolvem discussões direcionadas, como no caso da ideologia de gênero, e que necessariamente perpassam relação ao mundo e às suas transformações.

Esperamos que as discussões em torno da temática gênero e sexualidade permaneça ativas no âmbito das políticas públicas, de forma especial àquelas voltadas para a educação, uma vez que se faz necessário e urgente o envolvimento dos diversos segmentos na busca por uma sociedade mais democrática, capaz de olhar para seus sujeitos sem entenda que suas diferenças ou diminuem ou devem ser eliminadas.

Concluímos que essa perspectiva direciona nossa compreensão no sentido de que não podemos abrir mão de que questões dessa envergadura sejam retiradas dos currículos escolares e dos espaços formativos dos professores, pois estaremos favorecendo um espaço de fomento para um ideário centralizador, normatizante, com feições conservadoras que temos visto eclodir. 


\section{REFERÊNCIAS}

APPLE, Michael. Ideologia e Currículo. São Paulo, Brasiliense, 1982,

BHABHA, Hohmi K. O local da cultura. Belo Horizonte, Editora UFMG. 1998.

BAKHTIN, Mikhail. Marxismo e Filosofia da Linguagem. São Paulo: Hucitec, 1997.

BRASIL. Lei 9.394, de 20 de dezembro de 1996. Estabelece as diretrizes e bases da educação nacional. Diário Oficial da União. Brasília: Poder Legislativo, 23 dez. 1996, sec. I, n. 248, p. 27.833.

CHAUÍ Marilena. O que é ideologia. São Paulo, Brasiliense, 1985.

Convenção Americana sobre Direitos Humanos. Costa Rica, 1969.

GOMEZ, A. I. P. A cultura escolar na sociedade neoliberal. Porto Alegre: Artmed, 2000.

GUEDES, Neide C.; MONTEIRO, Adriana L.Profissionalidade docente: contribuições dos saberes e fazeres na construção do ser professor. Educere et Educare Revista de Educação, vol. 10, n. Especial, p. 433-444, jan./jun. 2015 .

LOPES, Alice C.; MACEDO, Elisabeth. Teorias de currículo. São Paulo: Cortez, 2011.

MACEDO, Elizabeth. Currículo como espaço-tempo de fronteira cultural. Revista Brasileira de Educação v. 11 n. 32 , p. 285-296, maio/ago. 2006.

MACEDO, Roberto S. A etnopesquisa crítica e multirreferencial nas crenças humanas e na educação. Salvador: EDUFBA, 2000

MOREIRA, Antonio F. B. O campo do currículo no Brasil: os anos noventa. In: Currículo sem fronteiras. v. 1, n. 1, p. 35-49, jan./jun. 2001.

PACHECO, José A. Políticas de integração curricular. Porto, Portugal: Editora Porto, 2000.

SILVA, T. T. O currículo como fetiche. Autêntica: Belo Horizonte, 1999.

SKLIAR, Carlos. Pedagogia improvável da diferença: e se o outro não estivesse aí? Rio de Janeiro: DP\&A Editora, 2003.

A educação que se pergunta pelos outros: e se o outro não estivesse aqui? In: LOPES, Alice Cassimiro; MACEDO, Elizabeth. (Orgs.). Curriculo: debates contemporâneos, São Paulo: Cortez, 2002. p. 196-215.

TERESINA. Câmara de Vereadores da cidade de Teresina. Projeto de Lei 20, de 22 de março de 2016. Veda (sic) a distribuição, exposição e divulgação de material didático contendo manifestações da ideologia de gênero nos estabelecimentos de ensino da rede pública municipal de Teresina.

TERESINA. Secretaria Municipal de Educação e Cultura. Diretrizes Curriculares do Município de Teresina, 2008.

VEIGA-NETO, A. Cultura e currículo. Contrapontos, vol. 2, n. 4, p. 43-51, 2002.

Currículo, cultura e sociedade. In: Revista Educação Unisinos. v. 05, n. 09, p. 157-171, jul./dez. 2004. 


\section{RESUMO}

O presente artigo objetiva discutir o avanço do conservadorismo no currículo da rede municipal de educação da cidade de Teresina, capital do estado do Piauí a partir do Projeto de Lei no 20/2016 aprovado pela Câmara Municipal que trata da proibição de livros, materiais didáticos ou qualquer outro meio contendo ideologia de gênero nas Escolas Infantis do município de Teresina. Para o desenvolvimento do estudo apresentamos os aportes teóricos que subsidiaram nossas discussões, dando destaque a Lopes e Macedo (2011), a partir das quais assumimos a compreensão sobre o currículo atravessado pela contradição diversidade/diferença. Argumentamos que essa perspectiva direciona nossa compreensão no sentido de que não podemos abrir mão de que questões dessa envergadura sejam retiradas dos currículos escolares e dos espaços formativos dos professores, pois assim cria-se um espaço de fomento do pensamento conservador.

Palavras-chave: Ideologia de gênero; currículo; Conservadorismo.

\section{GENDER DISCOURSE IN CURRICULUM OF TERESINA: REINVENTION OF CONSERVATIVE THINKING?}

\section{ABSTRACT}

This paper aims at discussing the advance of conservative thought in the educational curriculum developed and applied in the schools of the city of Teresina, capital of the state of Piauí, in Brazil's northeastern region. The argument present here stems from the city council approved \#20/2016 Law Project that strictly forbids children's books and educational resources from addressing gender ideology. The argument here developed is supported by Lopes and Macedo's previous work (2011), to whom the educational curriculum is necessarily imbued by the diversity/difference contradiction. The paper argues that Lopes and Macedo's perspective directs the understanding of the problem in the sense that it is considered unwise to dismiss gender ideology as a minor subject, removing it out from formative spaces, thus opening way to a more reactionary thinking.

Keywords: Gender ideology; curriculum; conservative thinking.

Submetido em Set./2016

Aprovado em Dez./2016 